\title{
The characterisation of organic components in the O- and E-stage bleaching effluent streams at Sappi Saiccor
}

\author{
B Moodley*, DA Mulholland and JJ Marsh \\ School of Pure and Applied Chemistry, University of Natal, Durban 4041, South Africa
}

\begin{abstract}
The major components from Sappi Saiccor's two bleaching streams of effluent were isolated and purified using chromatographic methods and characterised using NMR and other spectroscopic techniques. The major constituents extracted by organic solvents were identified as a sterol, fatty acids and lignin precursors and differ from the components identified in the pulping effluent stream.
\end{abstract}

Keywords: effluent, analysis, lignin, phytosterol

\section{Introduction}

Sappi Saiccor is one of the leading manufacturers of high-grade dissolving pulp using the acid sulphite pulping process. This highgrade quality pulp is produced by a number of steps including an elemental chlorine free (ECF) bleaching process. Recent trends towards environmental consciousness have prompted Sappi Saiccor to investigate ways of further reducing their effluent. In order to do this, the effluent must first be characterized and this has been the aim of this project.

Although much research has been carried out on Kraft effluent streams, very little research has been done on the bleaching streams of acid sulphite pulping plants such as Saiccor's. In addition, Saiccor uses hardwood as feedstock, resulting in different effluent composition as compared to most other dissolving pulp manufacturers that use softwood feedstock. These findings are important, as this is the first time that research into the characterisation of Saiccor's effluent has been carried out.

Sappi Saiccor uses a five-stage bleaching process to achieve a high-grade quality pulp. The introduction of ECF bleaching has resulted in reduced levels of resin in the mill's pulp and this has had a significant impact on the downstream manufacturing of products made from Saiccor's dissolving pulp (Weightman, 2000; Thubron, 2000).

The first stage in bleaching, stage $\mathrm{O}$, uses oxygen and sodium hydroxide, which removes some hemicellulose and low molecular weight cellulose. The $\mathrm{D}_{1}$ stage uses chlorine dioxide which solubilises the remaining lignin for the next stage. The E stage uses sodium hydroxide to dissolve the lignin. The $\mathrm{D}_{2}$ stage uses chlorine dioxide to whiten the pulp and break down any remaining lignin residues. The final stage is the $\mathrm{H}$ stage, which uses sodium hypochlorite to further whiten the pulp and chemically alter the molecular size of the cellulose (Weightman, 2000; Thubron, 2000). The final stage is the only stage that uses pure water - the other stages use water that is recycled counter-current. The $\mathrm{O}$ and $\mathrm{E}$ stage washings are the two contributors to the final effluent (Moodley et al., 2003).

\footnotetext{
* To whom all correspondence should be addressed.

嘼+2731 2603090; fax:+2731 2603091; e-mail: moodleyb3@nu.ac.za Received 28 June 2002; accepted in revised form 3 April 2003.
}

Previous research on the composition of other bleaching effluents revealed the presence of a variety of compounds such as fatty acids, sterols (sitosterol being the dominating component), lignin precursors and chlorinated and nonchlorinated phenolic compounds (Sjostrom and Alen, 1999). Compounds such as isomers of chloro$p$-methyl-isopropylbenzene, dichloro- $p$-methyl-isopropylbenzene and dichloro- $p$-methyl-isopropenylbenzene have been previously isolated from chlorine bleaching effluents (Bjorseth et al., 1977). The structure of many chlorinated aromatics formed in bleaching pulps has been determined by mass spectral studies (Knuutinen and Korhonen, 1984).

Holmbom (1980) carried out studies on the wastewater of bleached Kraft pulp from pine, spruce and birch in Finland. Gaschromatographic analysis of the methylated diethyl ether extract showed the presence of fatty acids (such as palmitic, stearic, oleic, conjugated linoleic,etc.), resin acids (such as secodehydroabietic, pimaric, palustric,etc.), diterpene aldehydes and epoxystearic acid. Analysis of the silylated diethyl ether extract showed the presence of phenols, chlorophenols (such as 2,3-dichlorophenol, 2,4,6trichlorophenol, 4,5-dichloroguaiacol, dichlorocatechol, tetrachlorocatechol, etc.), betulingenol, chlorodehydroabietic acids and sterols.

Studies by Lindstrom and Osterberg (1986) on softwood Kraft pulp bleach liquors have identified a large number of chlorinated acids including a new series of chlorinated keto acids. The chloracetic acids were found to be the major component but many chlorinated aromatics, such as, 2-furancarboxylic acid, chlorothiophenedicarboxylic acid and isomers of dichloro-4-hydroxy-3-methoxybenzoic and dichloro3,4-dihydroxybenzoic acids were present. The compounds were identified using gas chromatography-mass spectrometry and a total of thirty-one carboxylic acids were quantified.

In modern bleach plants the use of elemental chlorine has been drastically reduced or even completely eliminated (Gullichsen and Paulapuro, 2000). These pulp mills use chlorine dioxide as a bleaching agent instead of elemental chlorine, resulting in the formation of fewer chlorinated phenolic compounds (Deardoff et al., 1994). Mill trials carried out in three international paper company mills in the United States confirmed that the formation of polychlorinated phenolic compounds decreased with $100 \%$ chlorine dioxide substitution. 


\section{Experimental}

\section{Sampling and extraction of the O-stage bleaching effluent}

A $5 \ell$ sample of the $\mathrm{O}$-stage bleaching effluent was taken from the waste liquor going to the effluent drain after the pulp had been filtered. The sampling container was first rinsed with the sample to be taken and thereafter was filled. The sample had a much lighter colour than the calcium and magnesium samples, investigated previously (Moodley et al., 2003), and had a neutral $\mathrm{pH}$. The sample temperature was approximately $90^{\circ} \mathrm{C}$.

A $4 \ell$ sample of the cooled O-stage bleaching effluent was extracted with approximately twelve litres of chloroform, in portions, using a $6 \ell$ separating flask. The organic extract was evaporated using a BUCHI Rotavapor.

\section{Sampling and extraction of the E-stage bleaching effluent}

A $5 \ell$ sample of the E-stage bleaching effluent was taken from the waste liquor going to the effluent drain after the pulp had been filtered. The sampling procedure was carried out in the same manner as described for the sampling of the O-stage bleaching effluent. This sample was very much lighter in colour than the O-stage bleaching effluent as most of the unwanted materials had been removed in the previous bleaching and washing stages. The sample had a neutral $\mathrm{pH}$ and a temperature of approximately $90^{\circ} \mathrm{C}$.

A $4 \ell$ sample of the cooled E-stage bleaching effluent was extracted with approximately $12 \ell$ of chloroform, in portions, using a $6 \ell$ separating flask. The organic extract was evaporated using a BUCHI Rotavapor.

\section{Analytical procedures}

\section{General chromatography}

All compounds from both organic extracts, were isolated using gravity column chromatography and thin-layer chromatographic techniques. Gravity columns of 1 and $2 \mathrm{~cm}$ in diameter were used depending on the amount of sample available and final purifications were generally carried out on open $0.75 \mathrm{~cm}$ pasteur-pipette columns. All columns were packed with Merck Art. 9385 silica gel. The mobile phase for both column and thin-layer chromatography (t.l.c.) was varying ratios of dichloromethane, hexane, ethyl acetate and methanol. Thin layer chromatography was carried out on $0.2 \mathrm{~mm}$ silica-gel, aluminium-backed plates (Merck Art. 5554). The plates were developed with a mixture of anisaldehyde: concentrated sulphuric acid : methanol (1:2:97) spray reagent. They were first observed under UV (336 nm) and then heated to develop the colour.

\section{Nuclear magnetic resonance spectroscopy (NMR spectroscopy)}

Nuclear magnetic resonance spectroscopy was carried out on a 300 $\mathrm{MHz}$ Varian Gemini spectrophotometer and a $400 \mathrm{MHz}$ Varian UNITY-INOVA spectrophotometer. The spectra for all compounds were recorded at room temperature in deuterated chloroform $\left(\mathrm{CDCl}_{3}\right)$. The chemical shifts were all recorded in ppm relative to tetramethylsilane (TMS) signal. The spectra were referenced against the central line of the deuterated chloroform signal at $\delta_{\mathrm{C}}=77.2 \mathrm{ppm}$ and $\delta_{\mathrm{H}}=$ $7.24 \mathrm{ppm}$.

\section{Infrared (IR) spectroscopy}

The infrared spectra were recorded using a Nicolet Impact 400D Fourier-Transform Infrared (FT-IR) spectrometer, which was calibrated against an air background. The compounds were analysed using a sodium chloride window with dichloromethane as the solvent.

\section{Gas chromatography/mass spectrometry (GC/MS)}

All samples were introduced using a $1 \mu \ell$ auto injection system onto a HP5-MS column in the GC/MS with 1:75 split. The starting temperature was $50^{\circ} \mathrm{C}$, the sample was held for $2 \mathrm{~min}$, the temperature was ramped at $20^{\circ} \mathrm{C}$ per minute until it reached $300^{\circ} \mathrm{C}$ and thereafter the sample was held for another 2 min. Low-resolution mass spectrometry was carried out on an Agilent 5973 mass spectrometer connected to a $6890 \mathrm{GC}$.

\section{Preparative thin-layer chromatography (p.t.l.c.)}

Some compounds were purified using preparative thin layer chromatography. Samples, dissolved in a minimum of solvent (dichloromethane), were applied to the plates with the aid of a capillary tube. The plates were developed in a chromatography tank and the compound of interest was marked under UV. The marked bands were cut off the plate, extracted with methanol and thereafter the solvent evaporated to yield the desired compound.

\section{Results and discussion}

\section{The O-stage bleaching effluent}

The major extractive isolated from the O-stage bleaching effluent stream was identified as $\beta$-sitosterol (1). It is a common triterpenoid, and occurs widely in many plants and has previously been isolated and identified in bleaching effluent (Gullichsen and Paulapuro, 2000). The ${ }^{1} \mathrm{H}$ and ${ }^{13} \mathrm{CNMR}$ spectra as well as the infrared spectrum were used to identify this compound and its concentration in the $\mathrm{O}$ stage bleaching effluent was $0.0075 \mathrm{~g} / \ell$.

Hexadecanoic acid (3), more commonly known as palmitic acid, was also isolated and identified in this bleaching effluent stream having a concentration of $0.0088 \mathrm{~g} / \ell$. The mass spectrum showed a molecular ion peak at $\mathrm{m} / \mathrm{z} 256$, suggesting a molecular formula of $\mathrm{C}_{16} \mathrm{H}_{32} \mathrm{O}_{2}$. The matching fragmentation pattern in the GC/MS library identified this compound as palmitic acid. The ${ }^{1} \mathrm{H}$ and ${ }^{13} \mathrm{C}$ NMR spectra and the infrared spectrum confirmed its structure. Syringaldehyde $(0.0030 \mathrm{~g} / \ell)$ (2) was also identified in the O-stage bleaching effluent stream from ${ }^{1} \mathrm{H}$ and ${ }^{13} \mathrm{C}$ NMR spectra.

\section{The E-stage bleaching effluent}

9,12-Octadecadienoic acid (4), more commonly known as linoleic acid, was isolated and identified in the E-stage bleaching effluent having a concentration of $<0.0010 \mathrm{~g} / \ell$. The mass spectrum showed a molecular ion peak at $\mathrm{m} / \mathrm{z} 280$ and corresponded to a molecular formula of $\mathrm{C}_{18} \mathrm{H}_{32} \mathrm{O}_{2}$. The ${ }^{1} \mathrm{H}$ NMR spectrum was similar to that of palmitic acid showing the characteristic peaks of the methylene protons in the upfield region indicative of an aliphatic structure. The additional peak in the double bond region confirmed the presence of double bonds at positions 9 and 12 .

Other compounds also identified were $\beta$-sitosterol $(0.0043$ $\mathrm{g} / \ell)(\mathbf{1})$ and syringaldehyde $(<0.0010 \mathrm{~g} / \ell)(2)$, which had also been isolated and identified in the $\mathrm{O}$-stage bleaching effluent. 
(1)<smiles>CC[C@H](CC[C@H](C)[C@H]1CCC2C3(C)CC=C4CC(O)CC[C@]4(C)C3CC[C@]21C)C(C)C</smiles>

(2)<smiles>COc1ccccc1O</smiles>

(3)<smiles>CCCCCCCCCCCCCCCC(=O)O</smiles>

(4)<smiles>CCCCCC=CCC=CCCCCCCCC(=O)O</smiles>

Table 1 shows the concentrations of the quantities of these compounds passing to the effluent holding site, which were calculated based on the average plant effluent flowrates. These values suggest a significant quantity of these compounds passing out to the effluent holding site and extracting them would significantly reduce the amount of total dissolved solids in the effluent pumped out to sea.

\section{Conclusion}

The major compound isolated and identified in both the bleaching effluent streams was $\beta$-sitosterol. Other compounds present in the $\mathrm{O}$-stage bleaching effluent were palmitic acid and syringaldehyde. The E-stage bleaching effluent was also found to contain syringaldehyde as well as linoleic acid, which had not been isolated from the O-stage bleaching effluent. Thus, all the compounds isolated and identified have previously been isolated in bleaching effluent streams and that confirms earlier research carried out on this type of effluent from other plants. No chlorinated compounds were identified, as these are generally not present or present in very low concentrations in ECF bleaching processes (Sjostrom and Alen, 1999).

\begin{tabular}{|l|c|c|}
\hline \multicolumn{3}{|c|}{ TABLE1 } \\
$\begin{array}{c}\text { Calculated concentrations of the } \\
\text { compounds identified in both bleaching } \\
\text { effluent streams based on the stated } \\
\text { flow rates }\end{array}$ \\
\hline $\begin{array}{l}|c| \\
\text { Compounds } \\
\text { identified }\end{array}$ & $\begin{array}{c}\text { O-stage } \\
\text { bleaching } \\
\text { effluent } \\
\mathbf{( 1 6 0 \mathbf { ~ m } ^ { 3 } / \mathrm { h } )}\end{array}$ & $\begin{array}{c}\text { E-stage } \\
\text { bleaching } \\
\text { effluent } \\
\mathbf{( 1 6 0 \mathbf { ~ m } ^ { 3 } / \mathrm { h } )}\end{array}$ \\
\hline $\begin{array}{l}\text { Syringaldehyde } \\
\text { Sitosterol } \\
\text { Palmitic acid }\end{array}$ & $\begin{array}{c}0.480 \mathrm{~kg} / \mathrm{h} \\
1.20 \mathrm{~kg} / \mathrm{h} \\
1.40 \mathrm{~kg} / \mathrm{h}\end{array}$ & $\begin{array}{c}0.080 \mathrm{~kg} / \mathrm{h} \\
0.680 \mathrm{~kg} / \mathrm{h}\end{array}$ \\
Linoleic acid & & $0.080 \mathrm{~kg} / \mathrm{h}$ \\
\hline
\end{tabular}

\section{Acknowledgements}

This work was undertaken as a project for Sappi Saiccor and the funding of this project by Mr Derek Weightman of Sappi Saiccor is acknowledged. We are grateful to Mr John Thubron and Dr Tracy Pohl from Sappi Saiccor for providing the effluent samples and pulping process information provided, to Mr Dilip Jagjivan for the running of NMR spectra and to Mr Bret Parel for the running of mass spectra. We gratefully acknowledge the Wellcome Trust Equipment grant number 052451 for the provision of the $400 \mathrm{MHz}$ NMR spectrometer.

\section{References}

BJORSETH A, LUNDE G and GJOS N (1977) Analysis of organochlorine compounds in effluents from bleacheries by neutron activation analysis and gas chromatography/mass spectrometry. Acta Chemica Scandinavica B 31 (9) 797-801.

DEARDORFF TL, WILLHELM RR, NONNI AJ, RENARD JJ and PHILLIPS RB (1994) Formation of polychlorinated phenolic compounds during high chlorine dioxide substitution bleaching. Part 3: Mill trial results. Tappi 77 163-168.

GULLICHSEN J and PAULAPURO H (2000) Forest Products Chemistry. Fapet Oy, Helsinki. 93-97.

HOLMBOM B (1980) A procedure for the analysis of toxic compounds in pulp and paper mill waste waters. Paperi Ja Puu 9 523-531.

KNUUTINEN J and KORHONEN IOO (1984) Mass spectra of chlorinated aromatics formed in pulp bleaching. 2-chlorinated guaiacols. Organic Mass Spectrometry 19 96-100.

LINDSTROM K and OSTERBERG F (1986) Chlorinated carboxylic acids in softwood kraft pulp spent bleach liquors. Environ. Sci. \& Technol. 20 133-138.

MOODLEY B, MULHOLLAND DA and MARSH J (2003) Characterisation of organic components in the calcium and magnesium effluent streams at Sappi Saiccor. Water SA 29 (3)

SJOSTROM E and ALEN R (1999) Analytical Methods in Wood Chemistry, Pulping and Papermaking. Springer, Berlin. 238-252.

THUBRON J (2000) Personal communication. Technical Process Manager at Sappi Saiccor.

WEIGHTMAN D (2000) Personal communication. Technical Director at Sappi Saiccor. 